\title{
On Strengthening the Integration of Excellent Traditional Cultures into Ideological and Political Courses in High Education
}

\author{
Pan Xiangchao \\ Mianyang Teacher 'College ,Marxism School, Mianyang, Sichuan, China. \\ email,605081866@qq.com
}

Key Words: Ideological and Political Courses; Excellent Traditional Cultures; Integration; discussion

\begin{abstract}
At present, the university ideological and political class abstraction are not so efficient. The reasons are various. One of the main reasons is that the blending of traditional cultural factors in ideological and political course is too limited. Excellent traditional culture has very rich ideological indoctrination content. It is not only broad and profound, but also has interesting and strong ideological indoctrination function, some of which still has a very important significance. Strengthening the integration of excellent traditional culture into ideological and political course, not only can develop and utilize the ideological and indoctrination resources of excellent traditional culture, but also can improve the interests and effectiveness of the ideological and political courses. I try to discuss them from this aspects.
\end{abstract}

\section{在高校思想政治理论课中加强优秀传统文化融入的思考}

\author{
潘祥超 \\ 绵阳师范学院马克思主义学院, 绵阳, 四川, 中国 \\ email,605081866@qq.com
}

关键词：思想政治理论课；优秀传统文化；融入；思考

中文摘要. 目前, 高校的思想政治理论课理论性较强, 课堂实效性不理想。其原因可以说是 多方面的，其中一个非常重要的原因就是思想政治理论课传统文化因素融入得太少。优秀传 统文化中包含有十分丰富的思想教化内容, 其优点不仅在于博大精深, 而且富有趣味性以及 极强的思想教化功能, 其中有很多方面至今仍有十分重要的意义。在思想政治理论课中加强 优秀传统文化的融入，不仅仅可以挖掘、开发和利用优秀传统文化的思想教化资源，而且可 以大大的提高思政课的趣味性, 增强思政课的实效性。为此, 笔者试从这一视角进行一些有 益的探讨。

\section{1. 引言}

目前，高校思想政治理论课（以下简称思政课）的整体状况从有些方面来说不容乐观。 思政课就是老师在课堂教学上一味地讲解, 学生只是被动的接受; 从内容上来看, 有相当一 部分的思政课教师在教学中只是注重书本内容, 很少关注学生是否感兴趣。造成思政课出现 这种现状的原因是多方面的, 其中一个重要原因是目前 “思想政治理论课教材过于重视基本 原理、概念的解释和阐述, 使相当多学生认为思想政治理论课的内容空泛”, [1] 思政课中中 华上下五千年的优秀传统文化因素融入得不够。习近平指出: “中华优秀传统文化是中华民族 的突出优势，是我们最深厚的文化软实力。” [2] 中华民族的传统文化博大精深，历史悠久， 其广博的内容以及灵活生动的思想教化方法, 都值得我们当代人去学习、运用和发扬。在思 政课上加强融入优秀传统文化内容, 是增强高校思政课趣味性、知识性、高效性, 提高思政 课实用效果的一条重要途径。 


\section{2. 高校思政课中传统文化因素融入的现状}

“中国传统文化是用之不竭的源泉。但是严峻的现实状况是绝大多数高校忽视了中国传 统文化的主要作用”。[3]目前, 在高校思政课中, 传统文化内容的融入很少, 其主要表现在 高校思政课课程体系中所设置中的四门公共课传统文化科目的缺失和传统文化内容的缺失， 高校思政课教学中第一课堂、第二课堂和网络课堂中传统文化因素的缺失, 以及作为思政课 主体的学生的思想和行为中传统美德的缺失。

\section{1 课程体系设置中传统文化因素的缺失}

现行的四周可 “05 方案” 明确指出把 “原理”、“概论”、“纲要” 以及 “基础” 等作为大 学生思政必修课。我们从单科来看, 后三门都有一些章节涉及到传统文化的内容, 而 “原理” 也应该涉及到传统文化的内容, 因为马克思主义理论与中国哲学和传统文化有着千丝万缕的 联系。从课程设置来看, 高校并没有专门开设与传统文化有关的思想教育必修或者选修课程。 从这一现状说确实体现了当前课程及教材体系建设的缺憾。

\section{2 高校思政课堂教学传统文化因素的缺失}

目前, 在很大一部分高校的思政课课堂教学里存在的一个突出特点, 就是传统文化教育 在思政课中没有占到应有的地位和比例。高校的思政课课堂教学所涉及到的传统文化内容, 也仅仅只是局限在书本的某些章节提到的有限内容。近年来, 虽然部分高校也举办过一些有 关传统文化方面的论坛、专题讲座等活动, 但是这些活动学术性与专业性较强, 并且只是讲 座和论坛的性质。因此, 从实际效果上看, 这些活动对大学生的思想道德教育作用是非常有 限的。

\section{3 作为思政课教育主体的大学生思想和行为中传统美德的缺失}

大学生是思政课教育的主体，从现状来看，他们的思想以及由思想所表现出的行为中却 明显缺乏传统文化中所蕴含的优秀品德，主要体现在以下几个方面:

\section{3 .1 大学生社会公德的缺失}

也许在思想认识上, 在理论上, 大学生都清楚地明白在学校尊敬师长、团结同学、爱护公物 等, 在家要尊重长辈, 体谅父母的艰辛, 在公共场所要遵守公共秩序、维护公共卫生、言行 举止要符合社会文明等, 因为从小老师就在这样教育。但在实际行动上却做得不够好。这说 明我们在过度追求分数的时候, 一些中华民族的美德就慢慢被忽略了。对于进入大学, 马上 就要踏入社会的大学生来说, 加强这些传统美德的教育是势在必行的。

\subsection{2 诚信意识的缺失}

当前的大学生缺乏诚信的问题日益突出, 考试舞弊、找人代考、替人做 “枪手”、抄袭论文等 现象等屡见不鲜。有调查数据显示, “ $31.12 \%$ 的学生有过作弊行为”, [4] “对于拖欠国家助 学贷款和学生违约现象，有 9.09\%的反面数据”，也就是不按时偿贷款被纳入 “黑名单”, “有 51. 4\%的学生认为发生在校园中的考试作弊这种行为虽不道德, 但可以理解”, [5]而 2002 年 11 月 18 日，《中国青年报》刊登一所高校求职的学生中竟有近百名 “学生会副主席” 的新闻 报道。上述存在的现象, 反映了我们教育中存在的对传统文化中 “言必信, 行必果” 等理念 的缺失。

2. 3.3 艰苦朴素意识逐渐的淡薄。当前在校就读大学生大部分都是出生于上世纪 90 年代, 由 于社会经济条件的改善, 家庭生活环境越来越优越, 再加上社会上大环境的影响, 国家对人 民生活水平的关注等诸多因素, 这些没有吃过苦的学生艰苦朴素的意识逐渐淡薄。在生活上, 衣着讲高档, 聚会讲排场, 吃穿讲攀比, 玩乐讲多样, 消费讲超前, 推崇及时行乐。另外, 对于公共资源没有一个节约的意识。 


\section{3. 高校思政课中传统文化因素缺失的原因}

党和政府对于传统文化在思想政治教育中的所起的作用和功能也很重视，并先后出台了 一系列的决议和文件。从本文的第一部分分析可以看出, 目前在高校的思想政治课的教育中, 传统文化因素重视力度不够, 缺失明显。原因是多方面的, 但究其关键, 主要有以下几个方 面。

\section{1 党中央国务院的有关文件精神未能具体落到实处}

中央对中华传统文化因素在高校思想政治教育方面的重大作用这一问题高度重视，在党 的重要会议中屡次进行强调, 并且颁布了一系列的重要文件。习近平在十九七大报告中明确 指出: 我们要 “深入挖掘中华优秀传统文化蕴含的思想观念、人文精神、道德规范, 结合时 代要求继承创新, 让中华文化展现出永久鬼力和时代风采”, “推动中华优秀传统文化创造性 转化、创新性发展”，[6]要 “运用现代科技手段开发利用民族文化丰厚资源。”

中央对中华优秀传统文化在教育中的作用和功能的认识是非常深刻的, 并屡次强调要充 分利用中华民族优秀传统文化对大学生进行思想政治教育。各省级教育行政部门根据此颁布 的 “普通高校思想政治理论课建设标准” 也相应地很少涉及。这样的话, 不得不说是一种很 大的缺憾。

\section{2 高校教学重专业、轻思政，思政课重政治、轻思想的倾向越来越突出}

高校的思想政治课偏重于对大学生的革命传统教育, 带有政治性的内容明显重于优秀传 统文化的内容。在庆祝清华大学建校 100 周年大会上, 胡锦涛指出: “高等教育是优秀文化传 承的重要载体和思想文化创新的重要源泉”, “必须大力推进文化传承创新”。[7] 习近平在纪 念孔子诞辰 2565 周年国际学术研讨会讲话中指出: “中国优秀传统文化的丰富哲学思想、人 文精神、教化思想、道德理念等, 可以为人们认识和改造世界提供有益启迪, 可以为治国理 政提供有益启示，也可以为道德建设提供有益启发。” [8]因此，高校思政课理应把弘扬传统 文化作为提高大学生道德修养的重要内容。然而, 实际情况并不尽人意。从大学生的自身方 面看, 许多大学生为了就业, 就过分的重视对专业知识的学习, 他们把大量的课外时间集中 在英语四六级、三笔考试、普通话、计算机、考研、考公务员, 以及一些可以直接用于就业 的各种从业资格证的学习上，而一定程度上忽视了自身的思想道德素质修养与提高。

\section{3 兼有传统文化素质和马克思主义理论基础知识的师资队伍缺乏}

“高校思想政治理论课教师必须树立思想政治理论课融入优秀传统文化是其生命力所在 的理念。” [9] 从高校中从事思政课教学的教师队伍情况来看, 他们的传统文化理论知识水平 相对来说较低。这种状况的普遍存在，在很大程度上制约了高校思政课中马克思主义基本理 论与传统文化知识的有机结合，从而直接导致了高校里思政课传统文化因素的缺失。

\section{4 以思想教育为主旨的传统文化教材图书短缺}

截止目前，没有一本是由教育主管部门统一编写的、高校思政课通用的、以传统思想道 德教化为主要内容的教材。有些高校可能会结合当地和本校的实际情况, 编写一些选修教材, 并开展一些传统文化方面的讲座。但是, 从长远的、全面的眼光来看, 远远不能从根本上解 决问题。这在一定程度上也制约了传统文化对大学生道德素质的影响。

\section{4. 加强在思政课中融入优秀传统文化的路径}

在改革开放和实现中华民族伟大复兴的大好形势下，对待传统文化的价值，我们应该有 一个全新的、理性的认识。中华民族历史悠久的优秀的传统文化与马克思主义基本理论无论 是在内容上、功能上, 还是在价值取向上都具有高度的契合性, 关于这一点, 笔者在拙文《试 
论中华民族精神与马克思主义理论品质的契合共通》中已做了较为详尽的论述。这一契合性 给在思想政治教育理论课中融入优秀传统文化提供了可行性。在思政课中融入传统文化的资 源，可以从以下几个方面加强。

\section{1 加强和改进教材体系建设}

目前, 要在思政课教材中加大传统文化因素的融入力度, 可以从以下三个方面进行尝试。

4.1 .1 在现行的 “ $05 ”$ 方案的四门教材中加强传统文化因素的融入

目前这四本教材融入了中国传统文化内容较多的有两门, 即《纲要》课和《基础》课, 《概论》课在一定程度上有所涉及, 但所融入的内容相对较少。从目前四门课程融入的内容 来看, 远远不够, 都还有比较大的拓展空间。

\section{1.2 增加一些专门进行传统美德和思想教化的必修课}

为了加强大学生的传统思想道德教育, 可以考虑在现行的四门必修课之外, 再增加一些 专门进行传统美德教育与思想教化的必修课, 这些必修课可以涉及到中华民族优秀传统文化 中关于修齐治平、为人处世、物质利益观、自强不息、社会责任感、自信心、爱国主义、民 族自尊心和谐社会和大同社会等等内容。

\section{1.3 增设利用传统文化进行思想政治道德教育的选修课}

通过增设传统文化和思想政治教育衔接的选修课，以此来作为必须课必要的补充以及延 伸。开设这些必修课与选修课, 可以将一些传统文化中的思想道德教化内容直接传授给学生, 使之转化为学生的内在素质和学生的精神追求, 使更多的大学生能够领会传统文化的精髓, 弘扬中华民族的传统美德。

\section{2 加强师资队伍的建设，提高思政课教师的传统文化素养}

“教师是将传统文化与思想政治理论课融合的桥梁，也是开展融合的关键。”[10]高校思 政课教师首先应当不断的提高自己的传统文化素养，教师应在教学过程中，对传统文化知识 可以信手拈来。因此, 在思政课中加强传统文化因素的融入, 就必须打造一支具有过硬本领 的马克思主义理论修养, 同时还要具备坚实的、深厚的传统文化功底的复合型教师队伍。这 就要求:

\section{2.1 高校在马克思主义理论师资培养方面，应当加强对这种复合型人才的培养}

目前, 高校的马克思主义理论硕士点或博士点在培养高校教师的时候, 只注重这些研究 生对马克思主义理论的学习与研究, 而轻视了他们对传统文化的学习和研究。如果这一局面 能得到改善, 也是目前在大学生师政课教学中加强传统文化因素融入的重要途径之一。

\subsection{2 加强有传统文化功底的教师进入思政教师队伍}

可以考虑将目前高校文学院与历史文化学院部分有较高传统文化素养的教师引进到思政 课教师队伍中来, 从事一些专门的传统文化道德体系的工作。当然, 这一批教师同时还要加 强马克思主义理论的学习。

\section{3 深化教学模式的改革, 继续加强在思政课堂中传统文化因素的融入}

深化当前的教学模式的改革，在第一课堂、第二课堂和网络课堂中加强传统文化因素的 融入力度, 是加强对大学生进行传统文化与思想政治教育, 提高大学生道德素养的重要途径 之一，也是加强在思政课中融入优秀的传统文化因素的必然选择。在思政课的第一课堂、第 二课堂和网络课堂中融入传统文化的内容，是加强现有教材体系建设和师资队伍建设的必然 结果。 


\section{3.1 加强第一课堂优秀传统文化的融入}

在第一课堂中，教师可以充分的利用马克思主义基本理论课的主阵地主渠道的作用，有 计划有目的地把中华民族优秀的传统文化融入到第一课堂的教学过程中。采用具有民族形式 的风格语言去通俗地诠释马克思主义基本理论的深刻道理, 用马克思主义理论阐释优秀的民 族文化, 这样, 不仅传承和升华了中国民族传统文化, 还丰富和发展了马克思主义理论, 二 者相得益彰。

\section{3.2 加强第二课堂优秀传统文化的融入}

中国传统文化进入第二课堂, 可以引导学生诵读经典, 也可以带领学生们到历史文化遗 迹、博物馆等实地考察学习。这些历史文化遗迹和博物馆都是最好的传统文化教育和爱国主 义教育资源之一。这样可以有效地避免单调、枯燥的说教, 自然而然地提高了大学生对优秀 传统文化的兴趣和认知, 从而让学生们能够在生动活波、丰富多彩的德育教化形式中大大的 提高他们的学习兴趣, 并获取很好的德育效果。

\section{3 .3 充分利用思想政治教育的网络课堂的优势}

《国家 “十二五” 时期文化改革发展规划纲要》要求 “引导网络文化发展, 实施网络内 容建设工程, 推动优秀传统文化瑰宝和当代文化精品网络传播”。[11]利用网络来对大学生进 行思想政治教育，已经成为了高校思政课的重要途径之一，也为传播传统道德文化提供了便 利的条件。我们可以在原有的思想政治教育网络平台上开设一个优秀传统文化专栏, 这样大 大的推进在思政课中融入优秀传统文化的进程, 从而有效的提高大学生学习思政课的兴趣, 增强课程的实效性。

\section{5. 结束语}

毛泽东曾经指出: “我们这个民族有数千年的历史, 有它的许多珍贵品。从孔夫子到孙中 山, 我们都应当给以总结, 继承这一份珍贵的遗产”。[12]著名的国学大师季羡林说过, “在 中国传统文化地宝库中, 中国传统道德是最重要地一部分内容”。[13] “对大学生进行中华优 秀传统文化教育，是一项系统工程。” [14] “将中华优秀传统文化融人高校的思想政治理论 课堂教学中, 是一项提升思想政治理论教学有效性的重要措施。” [15]如何把这些优势转化成 丰富的思政课堂教学资源, 是我们的目标和努力的方向。在新时代建设中国特色社会主义的 重要历史关头, 要把当代大学生培养成社会主义建设者和合格接班人, 就必须深入研究中国 传统文化，把弘扬中华民族的优秀传统与新时代中国特色社会主义事业紧密地结合起来，从 长远的战略目标出发, 来寻求将二者结合契合点, 不断提升当代高校大学生思想政治理论课 时效性。

\section{致谢}

本文为绵阳师范学院 2012 年重点项目:中国传统文化与马克思主义时代化关系研究，编 号 2012B10; 绵阳师范学院高层次人才引进科研启动项目: 马克思主义三化与传统文化关系 研究, 编号 QD2012B04, 阶段性成果之一。

\section{References}

[1] Cao Yuchang, The combination of traditional culture and ideological and political theory in Colleges and Universities[J].Journal of Changchun Normal University, Vol.33,No.2,pp. 148-151,2014. 
[2] Xie Qi, The way of integrating excellent traditional cultural resources into the teaching of Ideological and political theory in Colleges and Universities[J].Education Teaching Forum, pp. 31-32,2018 (2).

[3] Tong Sisi, The theoretical basis for the integration of traditional Chinese culture and ideological and political theory courses[J].Theoretical Frontiers, pp. 86,2014(9).

[4] Cheng Zhengfang, The Investigation and analysis of contemporary college students' ideological situation[J]. Higher agriculture education, pp. 29-31,2005(8).

[5] $\mathrm{Xu}$ Tao, Yu Wanbin. An empirical study on the new characteristics of College Students' ideological status in Sichuan[J].Chinese youth research, pp. 66-69,2005(11).

[6] People's Daily online: Xi Jinping' Report at the 19th National Congress of the CPC. http://cpc.people.com.cn/n1/2017/1028/c64094-29613660.html

[7] Hu Jintao, Speech at the 100th anniversary celebrating the school of construction of Tsinghua University[N]. The people's daily, 2011-04-25.

[8] Xi Jinping: speech at the commemoration of the 2565th anniversary International Symposium on the birth of Confucius.

http://www.xinhuanet.com/politics/2014-09/24/c_1112612018.htm

[9] Xuan Fuying, Research on the integration of Ideological and political theory teaching and Chinese excellent traditional culture education[J]. Guangxi Education, pp.124-125,2015(8).

[10] Yuan Xiaowen, Thoughts on the integration of Chinese traditional culture and ideological and political theory courses in colleges and universities[J].Journal of Yunnan Institute of Socialism, pp. 258-259,2014(11).

[11] The Central People's Government of the People's Republic of China: http://www.gov.cn/jrzg/2012-02/15/content_2067781.htm

[12] Selected Works of Mao Zedong, Mao,BeiJing: People's Publishing House, pp. 534,1993.

[13] Ji Xianlin, On the Chinese culture[M].BeiJing:Hua Yi publishing house, pp. 8,2007.

[14] Cheng-yong chi, On the integration of Chinese excellent traditional culture and the teaching of Ideological and political theory in Colleges and Universities[J].Ideological \& Theoretical Education, pp.63-6,2014(12).

[15] Wang Xuan, Research on the integration of Chinese excellent traditional culture into the ideological and political theory course of colleges and universities [J]. Contemporary education practice and teaching research, pp.70,2016 (9) . 